\title{
JUVENTUDES, IDENTIDADES Y TRANSCULTURACIÓN. UN ACERCAMIENTO ANALÍTICO AL ROCK INDÍGENA EN CHIAPAS
}

\section{Youth, Identity and Acculturation. An Analytical Approach to Indigenous Rock in Chiapas}

\author{
Juan Pablo Zebadúa-Carbonell \\ Martín de la Cruz López-Moya \\ Efraín Ascencio-Cedillo
}

\begin{abstract}
Resumen: En este artículo se examina la producción de música rock indígena en Los Altos de Chiapas como un reflejo de procesos de cambio identitario juvenil. Se muestra que tales procesos no son simplemente la adopción (pasiva) de formas culturales musicales nacionales o internacionales que encuentranen suentorno oen los medios de comunicación, sino que son procesos creativos interculturalese intergeneracionales, basadosen sus propias raíces culturales en la búsqueda de su posicionamiento en tiempos de cambios sociales radicales. La música deestos grupos, en espacios públicos y virtuales ha sido catalizador, de oposición o de complementariedad. Se exploran temas como lo sagrado y lo profano, lo occidental y lo indígena, y se analizan los conflictos o encuentros entre lo moderno y lo tradicional.
\end{abstract}

Palabras clave: identidad cultural, cambio cultural, juventudes indígenas, rock indígena.

Abstract:This article examines the production of indigenous rock music in the Highlands of Chiapas as a reflection of processes of identity change among indigenous youth. As such, it attempts to show that these processes are not the simple adopting (passive) of non-indigenous cultural forms, either national or international, found currently in their surroundings or in accessible media, but rather that these processes are creative, constructive, and indicative of intercultural (and intergenerational) change which celebrate their own cultural roots, and attempt to define a position in the local or global context in these times of radical social change. The music of these groups, in public and virtual spaces, has been catalyzing, in opposition or in complement. Explore themes of the sacred vs. the profane, of occidental vs. indigenous, and analyze conflicts and similarities between modern and traditional.

Keywords: cultural identity, cultural change, rural youth, pop music.

Juan Pablo Zebadúa Carbonell. Doctor en Estudios Interculturales y Sociedades Multiculturales, por la Universidad de Granada, España. Profesor-investigador de la maestría en Estudios Culturales de la Universidad Autónoma de Chiapas, México. Temas de especialización: juventudes, identidades y consumos. Correo electrónico: jpcarboney@gmail.com.

Martín de la Cruz López Moya. Doctor en Ciencias Sociales con especialidad en Comunicación y Política por la Universidad Autónoma Metropolitana Unidad Xochimilco, México. Profesor-investigador del Centro de Estudios Superiores de México y Centroamérica de la Universidad de Ciencias y Artes de Chiapas, México. Temas de especialización: culturas urbanas, masculinidades y música popular. Correo electrónico: martindelacruzl@yahoo.com.mx.
Efraín Ascencio Cedillo. Sociólogo, fotógrafo y antropólogo social. Profesor-investigador del Centro de Estudios Superiores de México y Centroamérica de la Universidad de Ciencias y Artes de Chiapas, México. Temas de especialización: culturas urbanas, antropología visual y música popular. Autor de diversos artículos sobre música, etnicidades y consumos culturales. Correo electrónico: efrain.ascencio.cedillo@gmail.com.

Enviado a dictamen: 7 de abril de 2016 Aprobación: 10 de octubre de 2016. Revisiones: 1. 


\section{Globalización e identidades}

L o que a continuación presentamos se propone como una estrategia analítica para aproximarse a las juventudes étnicas, sus procesos identitarios y sensibilidades contemporáneas a partir de la observación y reflexión de sus prácticas musicales, particularmente de la producción, difusión y consumo de los bienes roqueros en contextos de alteridad, globalización y transculturalidad. La primera parte introduce un debate sobre la articulación entre las identidades y los procesos globales. En un segundo momento nos referimos a algunas concepciones de la etnicidad, sus significaciones y las identidades juveniles, para finalmente articularlas con la experiencia roquera que se gesta en y desde el estado de Chiapas después del levantamiento neozapatista de 1994.

En la historia reciente de las ciencias sociales los estudios sobre las identidades han adquirido mayor relevancia. Lo que estos estudios buscan es dar cuenta de las intensas recomposiciones socioculturales que se manifiestan a partir de los contextos globales, y también de la construcción de discursos de adscripción de los colectivos que, al mismo tiempo, connotan una pluralidad de pertenencias y configuran los sentidos de las sociedades actuales. Es por eso que el debate sobre las identidades se ha desarrollado a partir de sus referencias múltiples, revocando cada vez más las esencialidades de sus parámetros de demarcación y observando las diversas dinámicas que propician los cambios identitarios.

En el marco de las dinámicas globales, lasidentidades se conforman en procesos aparentemente fuera de foco de las directrices que normaban su anterior análisis. Desde los intercambios culturales generados en el mundo global, se han hecho evidentes los niveles de inserción que tienen los procesos de construcción identitaria en las miradas y perspectivas analíticas de las ciencias sociales que, a su vez, convocan a entender las complejidades del mundo contemporáneo:

En la actualidad, las identidades como noción epistemológica, estimulan el ímpetu de comprensión, y el despliegue de numerosas y diversas interrogantes societales que por mucho tiempo se mantuvieron velados por la obnubilación que provocaba el solo análisis de las representaciones identitarias, y las acciones que se le asociaban. Hoy las identidades, en su más amplia interpretación conceptual y metafórica, se ven enunciadas y/o manifestadas en todos los niveles del ámbito social (Gutiérrez, 2010: 13).

Por ello, esta problemática es un campo que genera una diversidad de abanicos analíticos, y uno de los fundamentales lo representa la perspectiva en la cual se sitúa la complejidad identitaria a partir de la difuminación de las fronteras que anteriormente se explicaban por sí solas. Las identidades se mueven y dinamizan; se transforman y transfiguran a una velocidad antes impensable y, así, los discursos, sean estos nacionales, regionales o locales, ya no son uniformes ni unívocos.

Este reordenamiento sistémico al que asistimos, que da pie a la reflexión sobre los caminos retomados por los grupos y sus recursos identitarios y de construcción de sentido, representa un contexto en el cual estas nuevas formas de posicionarse se reproducen sin distinción en procesos locales que igualmente tienen trascendencia con respecto a los globales, y viceversa. Es ahí donde se visibilizan las multiplicaciones de las identidades que son, al mismo tiempo, maneras de manifestar el sentido desde lo propio y de generar alternativas desde la adjudicación de formatos distintos a los originales y proponer así una amplitud en la forma de apropiarse de ellos.

Si las identidades no son esenciales ni inmutables, quiere decir que responden a contextos específicos y a realidades históricas cambiantes, por lo que los sujetos que las construyen tienen la capacidad de adaptarse y replantearse en función de sus necesidades individuales y grupales. Esto deviene en un intenso proceso de resignificación y cambio en las estructuras de sentido; su "desesencialización" actual responde a una posición relacional con las otredades al actualizar sus cualidades y valores:

Antes que entidades fijas e inmutables, las identidades 
son procesuales, están históricamente situadas [...] Las identidades son construcciones históricas y, como tales, condensan, decantan y recrean experiencias e imaginarios colectivos. Esto no significa que una vez producidas dejen de transformarse. Incluso aquellas identidades que son imaginadas como estáticas y ancestrales, continúan siendo objeto de disímiles transformaciones [...] En suma, las identidades nunca están cerradas o finiquitadas sino que siempre se encuentran en proceso, diferencialmente abiertas a novedosas transformaciones y articulaciones (Restrepo, 2012: 131).

Se trata de saber asumir el contacto con las otredades a partir de la pertenencia a una integridad cultural común, que se revalora y retransmite sin menoscabo de la pérdida del sentido primario de identidad.

\section{Identidades y procesos étnicos}

Este posicionamiento identitario "multiplicado" tiene repercusiones en los procesos de interacción interétnicos. El campo de lo étnico también se replantea a partir de los flujos e intercambios con que las identidades se arbitran, lo que da como resultado, entre otras cosas, la generación de otras perspectivas de análisis para entender su acontecer cultural y, en particular, de nuevas propuestas para ver cómo se desarrollan hoy tales identidades.

Por ejemplo, en muchos de los estudios antropológicos sobre procesos étnicos de antaño se enfatizaba que era inevitable la transformación de los indígenas debido al embate de la modernidad en cualquiera de los ámbitos de su influencia. Se hablaba de una "aculturación" irrevocable, mientras que los indígenas no eran más que receptores pasivos de esta reconversión cultural permanente y sistemática (Pérez, 2011: 70). No obstante, lo que ahora tenemos delantees la construcción de nuevos horizontes epistémicos para el estudio de las identidades étnicas, que se movilizan con adscripciones activas y en términos de agencia de los propios sujetos (Urteaga, 2011: 283). Se puede observar a las etnias con otro tipo de estrategias para encarar sus propios desarrollos y, desde luego, los alcances de sus identidades, refrendando así sus particulares posicionamientos culturales en el marco de los contextos actuales (Pacheco, 2010; Pérez, 2008). Todo lo anterior irá de acuerdo con lo que se puede obtener estratégicamente en la exhaustiva vinculación con lo global y aun cuestionando el propio término de "indígena", concepto que aglutina a un colectivo cultural, pero que no se determina por la propia adscripción, sino como un concepto impuesto desde afuera:

Cuando se les denomina indígenas, y ellos se asumen como tales, se hace referencia a una identidad producto de una hetero-denominación (primero impuesta y luego apropiada por unos), destinada a incluir y a reconocer dentro de ella a varios pueblos con culturas, lenguas e identidades diversas, y con lo cual, por lo demás, los externamente denominados indígenas pueden o no identificarse (Pérez, 2011: 67).

De por sí, esta posición estratégica de las etnias ha logrado su permanencia en el tiempo y en el espacio, pero ahora lo que se representa es la intensidad con que estos nuevos formatos aparecen como procesos culturales emergentes. Se generan así estrategias para la producción de la localidad (Appadurai, 2001). Por ejemplo, en el caso de la migración, la medición de su impacto tiene mucho que ver con estas reelaboraciones culturales que las comunidades indígenas llevan a cabo constantemente, dentro de sus propios entornos, así como con los nuevos contextos que se desarrollan producidos por los vaivenes de estas movilidades (Imaz, 2006: 237).

\section{Juventudes indígenas: campo emergente}

Ahora bien, lo anterior es evidente en los jóvenes indígenas, que también son continuos receptores de los elementos que la globalización oferta. De esta forma, poco a poco han ido ganando terreno las miradas con que se discuten estos nuevos actores, dado que su tratamiento en las discusiones actuales de los estudios étnicos es relativamente nuevo. Su visibilización se 
debe en gran medida a las prácticas culturales que estos jóvenes realizan en la actualidad, las cuales reproducen muchos elementos de sus ya evidentes procesos transculturales que, al mismo tiempo, son propuestas que aseguran sus inclusiones en las arenas globales.

Otro factor de gran relevancia es que la antropología ha dado un giro en sus horizontes explicativos y ahora voltea la mirada hacia otros sujetos que antes no tenían importancia para los análisis antropológicos (Guerrero, 2002; Hernández y Del Olmo, 2005: 19-26). Urteaga (2011) plantea tres grandes explicaciones por las cuales la literatura etnográfica sobre pueblos indios, en especial la antropología, había marginado al "sujeto joven indígena". La primera de ellas es que en muchos de los idiomas de las etnias nacionales no existe una nominación para el estadio de "la juventud", por lo que no existe como colectivo; la segunda es que la antropología, el campo de los estudios étnicos por excelencia, si bien menciona a las juventudes marginalmente y de manera sucinta, ha optado históricamente por una concepción de cultura como un todo cohesionado, donde no hay asomos de resquicios fuera de la convención comunitaria. Así, los jóvenes son invisibles porque la antropología priorizó los ritos de paso y las ceremonias de transición de la niñez a la adultez, pero no de la juventud al estadio adulto; la niñez y la juventud como etapas de "preparación" para llegar a ser adultos, hacerse "personas completas" (López, 2010) y "guardianes de la tradición". Por ello es necesaria, y he aquí la tercera explicación, una nueva concepción de cultura y un nuevo horizonte explicativo étnico que dé cuenta de estas porosidades con que se manifiestan los procesos indígenas (Urteaga, 2011).

En este sentido, resaltamos dos elementos que ahora aparecen como definitorios de las identidades juveniles indígenas. Por un lado, las adherencias a los medios masivos de comunicación, entre los que sobresalen las llamadas "redes sociales" y el uso intensivo del Internet (Morduchowicz, 2008; Medina, 2010; Romero, 2013) $y$, por otro, el consumo cultural, que aparece como una práctica por la que se aglutinan muchos de los procesos de subjetivación juvenil en los contextos globales. El consumo también constituye un recurso entre las juventudes para autorepresentarse: "el consumo como el conjunto de procesos socioculturales en que se realiza la apropiación y los usos de los productos" (García Canclini, 1995: 24). Estos dos elementos han dado un vuelco con respecto a la condición juvenil convencional de cara a las nuevas manifestaciones identitarias:

Frente a opiniones que consideran que la tendencia predominante es hacia la hibridación (en el sentido de collage arbitrario y sin sentido), la perdida de identidades propias, la adopción de identidades globales y deslocalizadas (varios trabajos) muestran cómo los procesos que se gestan entre los indígenas de América Latina no son unidireccionales ni producto de una oposición mecánica entre lo tradicional y lo moderno. Lo que se advierte, en cambio, es cómo ese poderoso flujo de modernidad que está presente en las comunidades indígenas, rurales y urbanas, puede producir el fortalecimiento de las identidades propias, además de generar nuevas formas de identidad y cultura (Pérez, 2008: 33).

\section{Juventudes y transculturalidad}

Sobre esto último quisiéramos ahondar más, en particular en el consumo musical del rock, en lo que se ha denominado rock indígena o etnorock. Para tal fin, enlazaremos tres conceptos que nos ayudarán a centrar el análisis transcultural de las identidades juveniles indígenas que se adscriben a este consumo.

La transculturalidad se propone aquí como un concepto en el que se pueden observar los procesos identitarios que acontecen en estos jóvenes, ya que se inscribe en lo que sucede en la interacción entre dos o más dimensiones culturales distintas. Si bien no es un concepto nuevo, ${ }^{1}$ es pertinente para proponer algunos horizontes sobre la condición juvenil indígena y las prácticas musicales (Quintero, 2009).

Dentro de los procesos de transculturación, las identidades múltiples se desarrollan como condición porque están dentro de un incesante marco de préstamos e intercambios culturales y, al mismo tiempo, cuando están en este marco de acción, llegan a crear un 
"tercer espacio": por un lado, está la cultura original en movimiento y comunicación constante; por el otro, los intercambios permanentes con otras culturas y formatos diversos, y, por último, como producto de todo el proceso emerge un nuevo constructo identitario que no pierde fuerza en tal reciprocidad cultural. Por el contrario, se enriquece y se retroalimenta constante y estratégicamente de los formatos primarios. De esta forma, los procesos transculturales se construyen en los intersticios del conflicto suscitado por las pertenencias identitarias, entre lo que es específico y lo que es distinto, para después elaborar los nuevos "constructos" identitarios.

Ahora bien, aquí nos referiremos a la transculturalidad identitaria desde los consumos musicales que, en concreto desde el rock indígena, se promueven a partir de la constante influencia de los medios de comunicación, las industrias culturales y el propio consumo musical. Son estos elementos los que conforman las complejas estructuras socio-tecnológicas que prácticamente delinean todo el sistema de información e intercambio de bienes culturales en el mundo: "Mediante la Internet también se tejen redes de conexiones tanto a nivel mundial como micro local. Las páginas oficiales de varios grupos se encuentran en inglés y español, con lo cual, evidentemente, intentan entablar comunicación con lectores fuera del bloque hispanohablante" (Martínez, 2013: 90).

En el caso de los jóvenes indígenas inmersos en estas apropiaciones mediáticas, que los convierten en receptores activos de los procesos de las industrias culturales, de los medios de comunicación y de las prácticas de consumo, también están en constante reciclamiento de tales discursos de acuerdo con sus propias estrategias culturales, y niegan así una supuesta uniformidad cultural étnica con su movilidad y transitoriedad identitaria. Son estos jóvenes un sector que acusa de manera crucial los cambios culturales a partir de los contextos de globalización y sus dinámicas emergentes:

De esta manera, el sector juvenil entre los indígenas existe porque interna y externamente se reconoce que existe, porque se habla de él y hay quienes se sienten parte de él, y porque al sentido de lo tradicional de ser joven se le están agregando nuevos valores y significados. Así que sobre el sustrato de una noción tradicional se están construyendo nuevas maneras de ver y sentir lo joven, y desde diferentes ámbitos (desde las escuelas, las iglesias, los medios de comunicación e información, la vida en las ciudades, etc.), a esa categoría se le están otorgando nuevas características de lo que significa ser joven; se están reformulando los parámetros para la asignación y la autoasignación de esa identidad, así como para definir las pautas de permanencia en ella, además de que, en forma creciente, es el punto de referencia para que un sector de la población construya acciones y demandas específicas (Pérez, 2008: 21).

\section{El rock como campo de consumo}

En el caso del consumo de la música rock en los jóvenes indígenas, la transculturalidad se percibe desde las propias condiciones en que lo consumen. Para tal fin, es necesario apuntalar tres aspectos que lo hacen atractivo a la hora de hacer del rock una música en la que se distingue una apropiación cultural sin igual en otro tipo de música juvenil indígena:

a. El rock como una manifestación artístico cultural, primeramente juvenil.

b. Como un espacio donde caben los discursos contraculturales, lo que ocasiona una forma más directa de expresión según la cual ir en contra de lo establecido es parte de la particularidad de ser roquero. Así, las entradas y salidas identitarias forman parte de estas acciones transculturales que construyen una forma de ser joven roquero indígena o músico en el marco de un consumo globalizado.

c. Como música transgeneracional, siempre cambiante y con disposición a nuevos formatos sonoros y de ser roquero. 
En cuanto al primer punto, a través del tiempo, el rock ha representado todo un movimiento cultural prácticamente sin precedente en ningún estilo musical contemporáneo. Este estilo sigue siendo un espacio discursivo juvenil por excelencia y, asimismo, una manifestación artística en la que las juventudes invocan la innovación y la expansión de las múltiples maneras de consumirlo y de resignificarlo. Entre todas las músicas, el rock sobresale justamente por esa característica, y son las juventudes las que se encargan de formatearlo de acuerdo con sus propias necesidades culturales y de generación de sentido: "El rock como práctica artística en México y en el mundo ha sido un territorio privilegiado de la revuelta juvenil" (Dela Peza, 2013: 37).

Del punto dos se desprende la existencia de mucha literatura, incluida la académica, que ha tratado de observar su influencia transgeneracional como movimiento, ya sea musical o social. El rock genera todavía mucha expectativa en cuanto a su esencia y a los formatos que propone para interpelar constantemente a las juventudes que acuden siempre a sus llamados discursivos, primeramente "contraculturales":

El rock es eminentemente una expresión estética musical. En primera instancia, es música que ha dado la pauta para crear espacios en los que convergen actitudes y relaciones sociales alternativas; desde su origen, manifiesta una actitud en la cual se producen formas de comportamiento y expresiones de inconformidad contra la moral y la cultura establecida. Es así que la rebeldía del rock daba a los jóvenes, y les sigue dando, con variaciones distintas a las de su contexto sociohistórico inicial, un espacio para expresarse en contra de las reglas y normas morales establecidas por la sociedad (Viera, 2011: 10).

Por otro lado, este campo contestatario permite niveles de transgresión discursiva que pueden ir desde lo político, hasta lo cultural. Es decir, si el rock se vislumbra como un espacio de creación estética musical donde se pueden romper normas establecidas, esto puede traer consigo que haya rupturas de toda índole.
En el caso de los jóvenes indígenas roqueros, esta postura permite ubicarse en cierto limbo identitario que ofrece la supuesta libertad del rock, lo que no pasaría, por ejemplo, en el caso de jóvenes indígenas que consumen y tocan música de banda o reggaetón. Si bien también son músicas ajenas a las "tradiciones comunitarias" étnicas, no existe una intención de reivindicación cultural ni política o de hibridaciones al respecto, lo que sí sucede en el rock, como bien enuncia De la Peza: "El rock en México ha sido un lugar de subjetivación política" (2013: 214).

Es decir, en la producción roquera en ámbitos indígenas de México convergen procesos globales, mediáticos, políticas culturales, nuevas formas de habitar las ciudades o las comunidades de origen y nuevas formas de autopercibirse y de narrarse que adoptan estos jóvenes en la contemporaneidad, lo que conduce a la aparición de un conglomerado de elementos culturales disímiles, que son apropiados por jóvenes indígenas que ven en el rock un espacio de interpelación para situarse en las complejas realidades que sobresalen actualmente.

Otro elemento que mueve a que estos jóvenes adopten este estilo musical que deviene en rock indígena o etnorock, como parte del punto tres, es su característica no esencializada del ser roquero. Existe rock para todos los gustos, además de que se puede cambiar cada vez que haya oportunidad por la simple razón de que, a través de sus años de historia, la música de rock es atemporal, transgeneracional y, como el ave fénix, resurge de su cenizas en una interminable renovación constante y en los entornos socioculturales más disímiles. Es atemporal porque, aun cuando tiene marcada una fecha específica en cuanto a sus raíces y su creación, traspasa la línea del tiempo y tras más de cinco décadas sigue tan actual como antes. También cruza transversalmente diversas generaciones, que lo continúan consumiendo, y siempre renueva sus vertientes y sus discursos: son ya cinco generaciones de adultos, jóvenes, adolescentes y hasta niños, las que se adscriben a esta música.

Las manifestaciones del rock son recurrentes en cuanto a sus propias formas de resignificarse y de 
adaptarse a los vaivenes de los tiempos actuales. Si bien ha habido acontecimientos o etapas furtivas en las que se ha declarado sistemáticamente su fin como una bandera generacional o ideológica (Zebadúa, 2011, 2002), la música rock ha sobresalido por su camaleónica forma de interpretar su acontecer y sobresale siempre como un arte que se ha derogado a sí mismo la condición de sobrevivencia a toda costa, a prueba de toda moda y de innovadoras y tecnologizadas formas de consumirlo. Los cambios por los que ha atravesado el rock en los planos internacionales tienen que ver con su turgente masificación a tal grado que, como nunca antes, se ha difundido a grandísimas escalas. Todo esto hace que la industria roquera se convierta a principios del siglo XXI en toda una institución musical. El cambio del rock ha hecho que en estos tiempos convivamos con sus nuevos rostros dentro de las dinámicas en las que acontece:

En México, los lugares sociales que el rock ha ocupado son muy diversos y aún opuestos, por lo que en su evolución este ha transformado su discurso y la forma de comunicarlo. Actualmente la cultura del rock ocupa una posición dinámica entre el entretenimiento masivo, la expresión popular disidente y la creatividad artística (Martínez, 2013: 13).

\section{Rock indígena: entre el son tradicional y la guitarra eléctrica}

Esto no pasa desapercibido entre los jóvenes indígenas, quienes también son depositarios de tales consumos a gran escala. En el caso del rock indígena o etnorock (López, Ascencio y Zebadúa, 2014), poco a poco se ha ido convirtiendo en todo un referente cultural entre jóvenes étnicos de todo el país y de varias regiones de Latinoamérica, lo que abre nuevos derroteros analíticos con los que percibir a la juventud indígena y los formatos identitarios con los que se adscriben y se insertan en el mundo global. A continuación haremos énfasis en la práctica del rock indígena de la región de Los Altos de Chiapas, territorio donde más impacto ha tenido en el sur de México y que se ha dimensionado a niveles internacionales.
Hasta hace un par de décadas el rock se mantuvo dentro de los entornos culturales de las grandes metrópolis y de los centros urbanos medios. Se podía constatar que, en tanto manifestación artística de gran despliegue mediático, estaba dentro de las esferas de producción de juventudes netamente urbanas y sus influencias y configuraciones sólo atañían a esos sectores que, marginales o no, devenían en actores de consumo roqueros a grandes escalas. Hoy, en cambio, emergen novedosas expresiones con diferentes estéticas y estilos en otros espacios, concretamente entre juventudes rurales o entre jóvenes hablantes de alguna lengua indígena, como ha ocurrido en algunas regiones de Argentina, Bolivia, Brasil, Colombia, Chile, Ecuador, Guatemala, Perú y en varias regiones indígenas de México.

Si bien la práctica del rock en México ha constituido un recurso creativo mediante el cual los jóvenes se narran a sí mismos dentro de las periferias de las industrias de la música - ya como contracultura, ya como discurso de impugnación, o como una "forma de vida" según los cánones tradicionales del ser roquero-, un complejo entramado de interacciones ha hecho posible que el rock haya encontrado nuevas formas de expresión entre juventudes indígenas a lo largo del territorio mexicano.

El rock, como práctica musical entre jóvenes indígenas, es una expresión cultural novedosa que desde hace ya casi veinte años ha venido a diversificar el paisaje musical del sureste mexicano. La puesta en escena del rock y de otros géneros afines como el hip hop, el ska o el reggae puede leerse como una manifestación de las sensibilidades musicales contemporáneas que posiciona a los jóvenes como agentes protagónicos de novedosas culturas juveniles. En términos generales, se trata de bandas de creación reciente que fusionan los ritmos del rock con instrumentos y armonías de la tradición musical de herencia maya, aquella que estuvo adscrita a los espacios ceremoniales.

En Chiapas son un poco más de quince bandas -y el número sigue aumentando- las que se han creado en municipios como Chamula, Zinacantán, Teopisca, Oxchuc, San Cristóbal de Las Casas, Las Margaritas 
y la región zoque. Desde entonces, los sonidos de este nuevo género pasaron a formar parte de los gustos musicales de muchos jóvenes indígenas y a recrear nuevos circuitos de difusión musical en esta región. Aparecen reiteradamente en las estaciones radiofónicas, en la televisión local, en las redes sociales o como música viva en festivales, conciertos o bares de San Cristóbal de Las Casas.

El gusto por el rock y la adopción de estilos de vida relacionados con este género entre grupos de jóvenes dejó de ser un asunto exclusivo de las grandes ciudades. En el caso de Chiapas, este incipiente movimiento musical lo protagonizan jóvenes tsotsiles y tseltales de Los Altos de Chiapas, y más recientemente hablantes de zoque y de tojolabal, entre quienes el rock se resignifica como un recurso de las manifestaciones juveniles, pero también como una estrategia de reivindicación étnica que proclama la defensa de las lenguas y de los usos y costumbres ancestrales.

En efecto, una de las características principales de esta práctica musical la constituyen las fusiones que estos jóvenes hacen entre las armonías de la música tradicional indígena - con instrumentos de uso ritual como tambores, arpas, guitarras y flautas de carrizo de fabricación local- con los ritmos del rock y los instrumentos electrónicos propios de este género: guitarra eléctrica, bajo y batería. Los nuevos roqueros cantan principalmente en tsotsil y tseltal, las lenguas mayas con mayor número de hablantes en Chiapas. Entre los contenidos de las canciones cantadas en su idioma podemos destacar las siguientes narrativas: el rock como recurso para hacerse visibles, evocaciones de su diferencia como jóvenes, imaginarios de sus experiencias amorosas, valoraciones de su pertenencia étnica y de su lengua, del cuidado ambiental y respeto a la naturaleza, de seres sagrados y de alabanza evangélica. Durante los conciertos realizan performances que proyectan elementos de la tradición a la que pertenecen y portan la indumentaria tradicional, especialmente de San Juan Chamula, Zinacantán y Oxchuc.

Esta nueva generación de jóvenes indígenas incorpora el rock, dentro de su abanico de gustos musicales, como una marca identitaria. Con esta nueva música, también nombrada como "etnorock" por los propios actores, asistimos a una dinámica de resignificaciones de la música tradicional indígena, aquella que antes estuvo reservada sólo para el ámbito ceremonial sagrado y ahora se pone en escena como un espectáculo fuera del contexto ritual.

En contra de lo que se observaba anteriormente con las diferentes censuras de las que fue objeto el rock en nuestro país, muchas iniciativas culturales dirigidas a los jóvenes alientan la creación de bandas de rock entre las poblaciones indígenas a lo largo del territorio nacional, promueven la producción discográfica y organizan festivales para su difusión e intercambio en distintas sedes a lo largo del país, como el concierto Tradición y Nuevas Rolas. Transformación y Fusión Sonora. Pero, más aún, esas preferencias, como escuchas o consumidores de esta música, las prolongan algunos otros como creadores o productores de rock. Junto con el boom, o aparejado a esta rápida eclosión, el cobijo de las políticas culturales ha capitalizado, en sus proyectos de promoción, gestión y preservación, el ingrediente étnico para generar espacios o facilitar los conciertos de rock y festivales que ya tienen amplia cobertura y difusión en la radio y la televisión estatal y nacional.

Un ejemplo de ello lo tenemos en el grupo Lumaltok, originario de Zinacantán, que "por su originalidad y calidad musical" fue incluido en la edición conmemorativa número 50 de la serie "Testimonio Musical de México, (1964-2009)" de la Fonoteca del Instituto Nacional de Antropología e Historia (INAH). Esta serie tiene la finalidad de preservar el patrimonio musical tradicional y popular del país. Pero también encontramos programas oficiales de cultura como el Programa de Apoyo a las Culturas Municipales y Comunitarias (PACMyC) del Consejo Nacional para la Cultura y las Artes (CONACULTA), que ha ofrecido apoyos económicos a diferentes solicitudes, entre las que podemos encontrar las de los músicos tradicionales o de rock. Además, los mismos grupos generan sus propias estrategias de posicionamiento y difusión, sus propios imaginarios ubicados en el tiempo y el espacio: vía web con páginas electrónicas personalizadas; a través de videos que suben a YouTube; creando su Metroflog o 
Blogspot; interactúan intensamente en redes sociales como Hi5, MySpace, Facebook, Goear o Twitter, ${ }^{2}$ y más recientemente en plataformas de servicio de música digital como iTunes y Spotify. En ellas encontramos sus perfiles, su producción discográfica y su calendario de "tocadas". Por ejemplo, el grupo Hektal escribe en su perfil de Facebook:

Hektal es una palabra maya que en español significa "ahorcarse", o como algunos medios lo han llamado: el proceso entre la vida y la muerte. Este proyecto comienza el 31 de diciembre del 2009 en un mágico pueblo, en la tierra del murciélago, Zinacantán, Chiapas. Bajo el nombre de ikal tzi que con el tiempo paso a ser Hektal. Este proyecto está conformado por cuatro jóvenes originarios de Zinacantan con el fin de hacer música original y expresar sus sentimientos por medio de la música. Mezcla tintes de la música tradicional zinacanteca y letras en tsotsil que es la lengua madre de Zinacantán. Las letras hablan de cosas que suceden en este pueblo, de las tradiciones entre otras cosas que con el tiempo se van olvidando, al igual, muchas hablan de ideas sobre la pobreza, el hambre, la guerra, y letras que tratan de hacer conciencia en la gente, ya sea para alentar o para evitar. Todo esto mezclado con el rock y tintes del reggae (www.facebook.com/hektalaguilar/about).

Ello trae consigo una serie de transformaciones, tanto en la diversificación de los circuitos musicales y de la noción de "músico indígena" como en las estrategias de producción y consumo musical entre los jóvenes. Aquí convergen distintos procesos: el redescubrimiento de lo "propio" y de las creaciones locales en términos musicales junto al recurso de una música híbrida que marca una diferencia cultural con la que los jóvenes resignifican lo indígena y con esto propician que las fronteras entre los géneros y tradiciones musicales se diluyan. En este nuevo imaginario de lo indígena y de "lo joven", el grupo de rock Lumaltok arguye lo siguiente: "Porque somos jóvenes tocamos rock y porque somos tsotsiles cantamos en nuestra lengua, nos sentimos orgullosos de nuestra cultura y de ser indígenas".

Hay aquí, como observamos, un diálogo con su historia y con su espacio social. Es una banda compuesta por cinco integrantes con edades entre los 16 y los 21 años que son originarios del municipio de Zinacantán. Su disco Son ik'al/Son de negros (2009) es también el nombre de uno de los sencillos que es retomado, a su vez, de una de las canciones locales tradicionales que se suele interpretar durante el carnaval; el grupo la incorporó a su repertorio, fusionándola con lo que ellos llaman "rock alternativo", "bats'i rock" o "rock verdadero". ${ }^{3}$

Si pensamos que una parte del rock se asume desde una postura de resistencia cultural y trata de recrear una visión utópica de sentimientos y relaciones sociales diferentes al imaginar mundos distintos y de espacios alternativos desde la música y las letras, entonces estas propuestas desde lo indígena tienen todos estos ingredientes tangibles desde lo audible y lo visible. Se genera todo un mundo de vida desde estos contextos socioculturales que se resignifican creando y recreando, a su vez, mundos simbólicos. Un ejemplo de ello: el grupo de hip hop Slajem Kóp, de San Juan Chamula, emplea todos los recursos del género, tienen sus MCing (rapping) y sus DJing (turntablism) que utilizan en una letra bilingüe tsotsil-español para hablarnos de todo este universo sociológico en una canción de rap:

Somos de una misma clase / los dialectos es lo que nos reconoce. Venimos de otra generación / tengo el orgullo de ser un descendiente maya y tener una mente clara. Escucha, siente mis palabras/reconozco de dónde vengo. Soy de un pueblo y me mantengo / hablo el idioma y me sostengo. Es un orgullo grande que yo tengo por dentro / un lenguaje, un idioma, un dialecto, diferente. Una burla es lo que florece mentalmente / español-tsotsil son los que yo represento para mi gente. Pasan y pasan los días en la tierra / un recuerdo siempre queda. Mi libreta no está llena / no perdamos nuestra lengua materna. Nuestra armadura es nuestra cultura en esta tierra / niño, joven, adolescente, piensa frecuentemente. Mi dialecto siempre estará presente / en cada calle, en cada plaza / mi dialecto siempre lo escucharé en 
todas partes. En esta vida nadie nace sabiendo dos idiomas es lo que yo represento / en este país, en este coro expreso mi raíz (grabación casera).

Vemos que la cultura y la identidad no son aspectos inamovibles o esencias naturalizadas, eternas o estáticas en la vida individual o colectiva. Hay un discurso de sentido de pertenencia: se sabe de dónde se viene, se siente orgullo por la lengua materna y se expresa la raíz primaria, como aquella canción que evoca "Una voz me ha dicho que no tenga miedo de ser indio". 4 Pero también observamos cambio, transformación e innovación al incorporar el hip hop como un recurso de identidad que les da la posibilidad de establecer pensamientos y delimitar sus actitudes, razones y sentimientos. Se contempla una reinvención, un reconocimiento de las raíces y una vista del pasado que los afirma en quienes son en el presente. Tenemos, entonces, a músicos indígenas que han ampliado sus fronteras musicales, mezcla de horizontes que les pueden ser cercanos o lejanos; están en él un conjunto de entramados culturales de los que se han apropiado, moviendo invariablemente lo que muchos pueden calificar como su centralidad étnica o etnocéntrica.

La pertenencia étnica imaginada como depositaria de saberes ancestrales en armonía con la madre tierra y la naturaleza forma parte de los discursos que los jóvenes roqueros difunden en las letras de sus canciones. En los mismos nombres de las bandas los jóvenes músicos imprimen esta idea: Sak Tzevul (Relámpago Blanco), Lumaltok (Niebla en la Tierra), Vayijel (Animal Guardián), Yibel Metik Balamil (la Raíz de Nuestra Tierra), Uyuj(Animal Espiritual), Yochob(Inframundo), Xkukav (Luciérnaga), Ik'al Joj (Cuervo Negro) y, uno de los más recientes, Ik’al Ajaw (El Señor Negro). Con estos recursos discursivos los roqueros indígenas reinventan la cosmovisión maya, imaginarios que presentan a la población indígena como portadora de elementos que han permanecido inmutables desde tiempos prehispánicos. ${ }^{5}$

En la construcción discursiva de este imaginario de lo maya jugó un papel importante la política indigenista y la antropología cultural que se hacía en Chiapas hasta los años setenta; sin embargo, esas mismas miradas se siguen reproduciendo en muchas publicaciones posteriores tanto académicas, como periodísticas o como parte del sentido común (Pitarch, 1995). Además, las perspectivas académicas fueron engarzándose en la población misma hasta interiorizarse en la memoria colectiva. Todo ello forma un corpus como parte del actuar individual y colectivo que, para los jóvenes y nuevas generaciones, dota de sentido a su vida misma: les hace pertenecer, se autoperciben, crean subculturas peculiares y únicas, les permite la producción de saberes, emociones, valores, cosmovisiones y aspiraciones.

Encontramos que la relevancia social y política de estas bandas de rock se sostiene en los discursos de identidad que expresan en las letras de sus canciones; pero, junto con ello, hay una exigencia sine qua non en este movimiento musical, que es una posición generacional de búsqueda y apertura que posibilitará a los jóvenes la apropiación de espacios públicos y nuevas formas de socialización, de producción y de consumo musical. Pero, sobre todo, un nuevo posicionamiento de su realidad como jóvenes indígenas. Precisamente, para muchos jóvenes la relación con el rock se significa como un recurso para la transformación de los gustos musicales, los cuales, en la mayoría de los casos, estuvieron anclados a los gustos de otras generaciones, principalmente por la canción ranchera, los corridos y la música tropical.

El rock en Los Altos de Chiapas también ha sido ese catalizador, en ocasiones, de oposición, en otras, de complementariedad; entabla una lucha conciliatoria o de desprendimiento, como ellos mismos dicen, entre lo "sagrado" y lo "profano"; es la exploración de "lo occidental" y "lo indígena", la tentación de "lo moderno" frente a "lo tradicional".

Estos imaginarios del rock, que se articulan con los imaginarios locales de la tradición, son representaciones parciales que se asocian o se concatenan con otras representaciones igualmente parciales, dúctiles, inestables, transformables históricamente, construidas socialmente. Tienen una interacción constante unas y otras, son a su vez de longitud y perímetros variables (Giménez, 2007). Estamos frente a una plasticidad de lo social, frente a una forma de doxa o de estereotipo por 
el cual se crean esos relatos imaginarios organizados y coherentes de la vida, de la realidad pretérita, presente y hasta futura. Esos imaginarios contribuyen a gestar identidades que se quieren comunes, que participan de las mismas creencias; imaginarios que los identifican como parte de una afrenta — de más de 500 años — o del júbilo colectivo, de algo que sólo será propio del grupo, su huella y su marca.

Si lo observamos en perspectiva, la historia del rock en Chiapas ya ha sido diferente desde que surgieron bandas entre la población indígena porque este movimiento vino a diversificar la tradición musical étnica, siempre reducida a la vida ceremonial o a la cultura ritual de estos pueblos. Si bien este rock surge como una estrategia que pretende la salvaguarda de ciertos saberes ancestrales, este movimiento cultural también hizo visible a Chiapas en términos de dicho género musical. Los discursos ecológicos, las costumbres ancestrales, la mística maya, las "buenas vibras", la paz, los derechos humanos, el respeto a la diferencia, etcétera, fueron elementos que alearon una nueva determinante social.

Los procesos transculturales devienen en la creación de nuevas perspectivas identitarias en los jóvenes indígenas roqueros, por lo que nos encontramos frente a una necesaria postura crítica en cuanto a lo que se percibe como un cambio de visión de las culturas denominadas "originarias". El rock indígena, como campo de consumo, permite la flexibilidad de los límites de adscripción con los cuales se entendía a estos jóvenes. Al integrar el rock dentro de sus prácticas musicales y fusionarlas con los sonidos de las tradiciones musicales de sus pueblos, estos jóvenes se asumen como ciudadanos del mundo, con agencia social, y se posicionan como actores étnicos que conciben una nueva forma de representarse y de incluirse como parte de las permanentes reconfiguraciones sociales que acontecen en los panoramas socioculturales de las sociedades actuales.

\section{Notas}

${ }^{1}$ El concepto de transculturación se atribuye por primera vez al antropólogo cubano Fernando Ortiz, en 1940, quien lo consigna para superar el de "aculturación", muy en boga por esos tiempos dentro del campo antropológico. Esta nueva noción conceptual fue validada por Bronislaw Malinowski en el prólogo al libro clave de Ortiz Contrapunteo cubano del tabaco y el azúcar (1978). Dijo el antropólogo con respecto a la transculturación: "Es un proceso en el cual siempre se da algo a cambio de lo que se recibe, es un 'toma y daca', un proceso en el cual ambas partes de la ecuación resultan modificadas. Un proceso en el cual emerge una nueva realidad que ni es una aglomeración mecánica de caracteres, ni siquiera un mosaico, sino un fenómeno nuevo, original e independiente".

${ }^{2}$ Algunos ejemplos del uso de las redes sociales por estos grupos son los siguientes: Lumaltok en Facebook (https://www.facebook.com/lumaltok.rocktsotsil) y en YouTube participando en un festival local (http:/ www. youtube.com/watch?v=1KdDDoK4fl4\&efeature=relat ed), en Myspace han subido sus pistas en MP3 (http:// www.myspace.com/lumaltok), o en páginas como Goear (http://www.goear.com/search/Lumaltok/); Sak Tzevul tiene Myspace (http://www.myspace.com/ saktzevul) y Facebook (https://www.facebook.com/ pages/Sak-Tzevul-Oficial/201650402108). Esta banda fue una de las primeras en tener página web (http:// www.saktzevul.com/) y, por supuesto, los podemos ver en videos desde la plataforma de YouTube (http:// www.youtube.com/watch?v=GizEOeEbcfw).

${ }^{3}$ Estos discursos se pueden leer en las portadas de los discos que producen estas bandas. Ver, por ejemplo, el disco Vukubja 'vil ta Lumaltok, publicado en 2015.

${ }^{4}$ Sak Tzevul, "Voz entre mis sueños" del álbum $X_{\text {ch'ulel }}$ Balamil (2009).

${ }^{5}$ Ver documental Música de adentro: es música que hereda, es rock tzotzil (2012).

\section{Referencias bibliográficas}

Appadurai, Arjun (2001). La modernidad desbordada. Dimensiones culturales de la globalización. Buenos Aires: FCE/Trilce.

Arfuch, Leonor (2001). "Escenario urbano e identidad cultural”. En Marta M. Palchevich y Luis H. Martínez 
(coords.), Boletín de la Biblioteca del Congreso de la Nación No. 120. Identidad cultural. Buenos Aires: Biblioteca del Congreso de la Nación, pp. 61-74.

De la Peza Casares, María del Carmen (2013). El rock mexicano. Un espacio en disputa. México: Universidad Autónoma Metropolitana-Unidad Xochimilco.

García Canclini, Néstor (1995). Ciudadanos y consumidores. México: Grijalbo.

Giménez, Gilberto (2007). Estudios sobre la cultura y las identidades sociales. México: CONACULTA/ITESO.

Guerrero Arias, Patricio (2002). La cultura. Estrategias conceptuales para comprender la identidad, la diversidad, la alteridad y la diferencia. Quito: Abya-Yala.

Gutiérrez Martínez, Daniel (coord.) (2010). Epistemología de las identidades. Reflexiones en torno a la pluralidad. México: UNAM.

Hernández, Caridad y Margarita del Olmo (2005). Antropología en el aula. España: Síntesis.

Imaz Bayona, Cecilia (2006). "Multiculturalismo y migración internacional. Permanencia y revaloración de la identidad cultural de la migración mexicana en los Estados Unidos". En Daniel Gutiérrez Martínez (coord.), Multiculturalismo: perspectivas y desafíos. México: UNAM, pp. 225-240.

López Moya, Martín de la Cruz (2010). Hacerse hombres cabales. Masculinidad entre tojolabales. México: CIESASUNICACH.

López Moya, Martín de la Cruz, Efraín Ascencio Cedillo y Juan Pablo Zebadúa Carbonell (coords.) (2014). Etnorock. Los rostros de una música globalen el Sur de México. México: CESMECA-UNICACH/Juan Pablos Editor.

Martínez Hernández, Laura (2013). Música y cultura alternativa. Hacia un perfil de la cultura del rock mexicano de finales del siglo $X X$. México: Universidad Iberoamericana/ITESO.

Martuccelli, Danilo (2010) "Los tres ejes de la identidad". En Daniel Gutiérrez Martínez (coord.), Epistemología de las identidades. Reflexiones en torno a la pluralidad. México: UNAM, pp. 61-75.

Medina, Gabriel (2010). "Tecnologías y subjetividades juveniles”. En Rossana Reguillo (coord.), Los jóvenes en México. México: FCE, pp. 154-182.
Marín Gracia, María Ángeles (2002). "La construcción de la identidad en la época de la mundialización y los nacionalismos". En Margarita Bartolomé Piña (coord.), La identidad y ciudadanía. Un reto a la educación intercultural. Madrid: Narcea, pp. 27-49.

Morduchowicz, Roxana (coord.) (2008). Los jóvenes y las pantallas. Nuevas formas de sociabilidad. Argentina: Gedisa.

Pacheco Ladrón de Guevara, Lourdes C. (2010). "Los últimos guardianes. Jóvenes rurales e indígenas". En Rossana Reguillo, Los jóvenes en México. México: FCE, pp. 124-153.

Pitarch, Pedro (1995). "Un lugar difícil: estereotipos étnicos y juegos en Los Altos de Chiapas". En Juan Pedro Viqueira y Mario Humberto Ruz (eds.), Chiapas: los rumbos de otra historia. México: CIESAS/UNAM.

Pérez Ruiz, Maya Lorena (coord.) (2008). Jóvenes indígenas y globalización en América Latina. México: INAH.

Pérez Ruiz, Maya Lorena (2011). "Retos para la investigación de jóvenes indígenas”. En Alteridades Jóvenes en América Latina. Abordajes desde la antropología, 42: 65-75.

Quintero Rivera, Ángel (2009). Cuerpo y cultura. Las músicas mulatas y la subversión del baile. Madrid: Editorial Iberoamericana.

Restrepo, Eduardo (2012). Intervenciones en teoría cultural. Colombia: UC.

Romero Orduña, Linda Margarita (2013). La sociabilidad del joven poblano en el Facebook. Tesis de Maestría, BUAB, México.

Terrazas Merino, Maziel (2008). "Jóvenes quechuas del ayllu Chari, La Paz, Bolivia: identidad, globalización, imaginarios y bienes culturales". En Maya Lorena Pérez Ruiz (coord.), Jóvenes indígenas y globalización en América Latina. México: INAH, pp. 141-160.

Urteaga Castro-Pozo, Maritza (2011). La construcción juvenil de la realidad. Jóvenes mexicanos contemporáneos. México: UAM/Juan Pablos.

Valenzuela, José Manuel (2009). El futuro ya fue. Socioantropología de l@s jóvenes en la modernidad. México: COLEF/Juan Pablos. 
Viera Alcázar, Merarit (2015). Jóvenes excéntricas: cuerpo, mujer y rock en Tijuana. México: Casa Editorial Abismos.

Zebadúa Carbonell, Juan Pablo (2011). El rock de fin de siglo. 22 años de análisis de las identidades y el cambio en la música del rock. México: AGYS ALEVIN.

Zebadúa Carbonell, Juan Pablo (2002). Rock y contracultura. La apropiación cultural del rock por parte de la juventud contemporánea. México: IVEC.

\section{Medios audiovisuales}

Lumaltok (2015). Vakub Ja'vil ta Lumaltok [CD audio]. México: CONACULTA/Cultivarte Studio

Música de adentro: es música que hereda, es rock tzotzil [documental] (2012). Veracruz: Universidad Cristóbal Colón.

Sak Tzevul (2009). Xch'ulel Balamil. Poema rockofónico [CD audio]. México: National Museum of Mexican Arts. 